\title{
RESEARCH
}

Open Access

\section{Sex differences in the management of persons with dementia following a subnational primary care policy intervention}

Nadia Sourial ${ }^{1,2^{*}}$, Geneviève Arsenault-Lapierre ${ }^{3}$, Eva Margo-Dermer ${ }^{4}$, Mary Henein ${ }^{3}$ (D) and Isabelle Vedel ${ }^{3,4}$

\begin{abstract}
Background: The influence of sex and gender on the risk of dementia, its clinical presentation and progression is increasingly being recognized. However, current dementia strategies have not explicitly considered sex and gender differences in the management of dementia to ensure equitable care. The objective of this study was to examine the moderating effect of sex on the quality of care following the implementation of the Quebec Alzheimer Plan (QAP).

Methods: We conducted a secondary analysis of the evaluation of the QAP consisting of a retrospective chart review of 945 independent, randomly-selected patient charts of males and females $75+$ years old with dementia and a visit to one of 13 participating Family Medicine Groups before (October 2011-July 2013) and after (October 2014 - July 2015). The quality of dementia care score, based on Canadian and international recommendations and consensus guidelines, consisted of documented assessments in 10 domains. We used a mixed linear regression model to measure the interaction between sex and the implementation of the QAP on the quality of dementia care score, adjusting for age and number of medications.

Results: We found that improvements in the quality of dementia care following the QAP were larger for men than women (mean difference $=4.97 ; 95 \% \mathrm{Cl}: 0.08,9.85$ ). We found that men had a larger improvement in four indicators (driving assessments, dementia medication management, Alzheimer Society referrals, and functional status evaluation), while women had a smaller improvement in three (home care needs, behavioural and psychological symptoms of dementia, and weight). Men were prescribed fewer anticholinergics post-QAP, while women were prescribed more. Cognitive testing improved in men but decreased for women following the QAP; the opposite was observed for caregiver needs.

Conclusion: While the overall quality of care improved after the implementation of the QAP, this study reveals differences in dementia management between men and women. While we identified areas of inequalities in the care received, it is unclear whether this represents inequities in access to care and health outcomes. Future research should focus on better understanding sex and gender-specific needs in dementia to bridge this gap and better inform dementia strategies.
\end{abstract}

Keywords: Sex, Gender, Equity, Health policy, Evaluation

\footnotetext{
* Correspondence: nadia.sourial@umontreal.ca

'Département de Médecine de Famille et de Médecine d'Urgence, Faculté de médecine, Université de Montréal, Montreal, Canada

${ }^{2}$ Centre de Recherche du Centre Hospitalier de l'Université de Montréal, Université de Montréal, Montreal, Canada

Full list of author information is available at the end of the article
} 


\section{Background}

Sex and gender are recognized as major drivers of health inequities [1-5]. For example, differences in health seeking behavior, access to informal caregivers, financial and social resources among men and women have been shown to create health disparities in access to care and health outcomes, especially affecting older women [6-9]. As such, the importance of integrating sex and gender in health research to prevent inequities in care is increasingly being recognized for sound evidence-based practice and policy [10, 11]. In particular, consideration of these issues in the development and implementation of health interventions has been advocated to ensure interventions are equitable and adapted to meet the needs of both men and women [12].

The influence of sex and gender is particularly relevant in dementia care. Evidence is emerging on the influence of sex and gender on the risk of dementia, its clinical presentation and progression [13]. Dementia disproportionately affects women, who account for 2 in 3 cases [13]. This higher prevalence has not only been attributed to women living longer on average than men but also due to underlying differences in disease and/or sex and gender-related risk factors [13-15]. For example, older women are more likely to have a lower educational attainment and engage in less exercise, both risk factors for dementia, due in part to historically greater parental roles in women than in men [16]. Women, who carry a greater caregiving burden, also have twice the risk of developing depression, a major risk factor for dementia, compared to men [16, 17].

In terms of the clinical presentation and progression of dementia, women tend to perform better on cognitive tests than men due to improved reserves in verbal memory [18]. As a result, women tend to be diagnosed later in the disease, leading to delayed management and more rapid decline after diagnosis than men [13, 18-20]. On the other hand, men with dementia have been shown to have a higher prevalence of severe comorbidities [21-24], and a higher likelihood to develop aggressive behavioral and psychological symptoms of dementia [25, 26]. Finally, as seen in the general older population, gender differences have been shown in men and women with dementia in terms of access to care, financial and social support $[13,14]$.

These sex and gender differences in dementia may require different approaches to the management of dementia. However, the role of sex and gender has been largely neglected in national and subnational dementia strategies seeking to improve the quality of dementia care through better detection, diagnosis and management of persons with dementia [27]. Only the most recent dementia strategies and plans consider differences in risk and health disparities based on sex and gender in their action plan but none explicitly discuss how sex and gender should be considered in the management of dementia to ensure equitable care $[27,28]$.
One subnational dementia care intervention, the Quebec Alzheimer Plan [29], aimed at improving dementia care in the primary care setting, was recently evaluated. The Quebec Alzheimer Plan was initiated in 2014 and is being implemented in Family Medicine Groups, primary care interdisciplinary clinics, across Quebec, Canada. It aims to enable and empower primary care clinicians to detect, diagnose, treat and follow-up patients living with dementia and their caregivers, while allowing for local adaptations, by providing financial support and training. The pilot phase of its implementation was previously evaluated and found to improve the quality of dementia care within primary care [30]. Further details on the intervention and early evaluation are available elsewhere $[30,31]$. However, whether changes in the quality of dementia care were similar in both men and women have yet to be explored. Understanding potential sex differences is essential to adapt such ongoing strategies to ensure equity in their implementation and scale-up. The objective of this study was therefore to examine the moderating effect of sex on the impact of the Quebec Alzheimer Plan (QAP) on the quality of dementia care.

\section{Methods}

\section{Setting, design and population}

This study is a secondary analysis of the evaluation of the QAP which consisted of training and funding for primary care clinics in Quebec, Canada's second largest province accounting for one-quarter of the population [32], to improve the quality of care of persons with dementia. Implementation of the QAP took place between 2014 and 2015. The evaluation was conducted through a retrospective chart review of 945 independent, randomly-selected patient charts of males and females 75 years old and older with dementia (including mild cognitive impairment) and with a visit to one of 13 participating clinics before (preperiod: October 2011-July 2013) and after (post-period: October 2014 - July 2015) the implementation of the QAP [30]. Further details are available elsewhere [30].

\section{Study variables}

Information on age, sex, living arrangement, the number of medications, the prevalence of antipsychotic use, and the type of dementia were collected from patient charts.

The study outcome was the quality of dementia care as measured by a score based on Canadian and international recommendations and consensus guidelines for the care of persons with dementia [29, 33-35]. This score consisted of documented assessments in the following 10 domains: cognitive testing, evaluation of functional status, behavioral and psychological symptoms of dementia (BPSD), weight, caregiver needs, driving status, home care needs, community service needs (e.g. Alzheimer Society), absence of anticholinergic medication, and 
management of dementia medications. The score was calculated by summing the number of indicators performed divided by the number of eligible indicators for each patient. Patients' eligibility for each indicator (for example a patient who is no longer driving would not need a driving evaluation) was assessed over the study period.

\section{Analysis}

Patient characteristics before and after the QAP were described stratified by sex. A mixed-effect linear regression model was used to model the interaction between sex and the implementation of the QAP on the quality of dementia care score, adjusting for age and number of medications. A sensitivity analysis further adjusting for living arrangement was also conducted. As patients within clinics were likely to be more similar than patients across clinics, an identifier for the clinic was included as a random effect in the model to account for the effect of clustering on the variability in the data. Adjusted means and associated 95\% confidence intervals were derived from the model. A bar graph was used to illustrate the frequency of each of the 10 quality of care indicators for both men and women and in both study periods.

\section{Results}

Differences in the characteristics of men and women were comparable in the pre and post period (Table 1). Women accounted for a majority of the sample, $63 \%$ in the pre-period, $61 \%$ in the post-period. In each period, women were on average 1 year older than men and were taking one additional medication than men. We observed more cases of Alzheimer's disease in women, while men had a higher prevalence of mixed dementia. A greater proportion of women in our study lived alone or with someone else other than a spouse or child than men (Table 1).

Figure 1 presents the adjusted mean quality of dementia care score for men and women, pre and post-QAP implementation. While the score in the pre-period was similar for men and women (48.4 vs. 48.2), a greater increase in the score was observed in men than in women in the post period (57.9 vs. 52.8 ). This interaction between sex and the implementation of the QAP was found to be statistically significant (mean difference: 4.97, 95\% CI: 0.08, 9.85; Table 2). The sensitivity analysis showed a similar interaction estimate between sex and the implementation of the QAP when accounting for living arrangement (mean difference 5.18; 95\% CI: $0.28-10.08)$.

Table 1 Patient characteristics

\begin{tabular}{|c|c|c|c|c|}
\hline & \multicolumn{2}{|c|}{$\begin{array}{l}\text { Pre-QAP Implementation } \\
N=455\end{array}$} & \multicolumn{2}{|c|}{$\begin{array}{l}\text { Post-QAP Implementation } \\
N=490\end{array}$} \\
\hline & $\begin{array}{l}\text { Men } \\
n=169(37 \%)\end{array}$ & $\begin{array}{l}\text { Women } \\
n=286(63 \%)\end{array}$ & $\begin{array}{l}\text { Men } \\
n=190(39 \%)\end{array}$ & $\begin{array}{l}\text { Women } \\
n=300(61 \%)\end{array}$ \\
\hline $\begin{array}{l}\text { Age in years, } \\
\text { median (min-max) }\end{array}$ & $\begin{array}{l}83.1 \\
(75.0-99.5)\end{array}$ & $\begin{array}{l}84.3 \\
(75.0-102.0)\end{array}$ & $\begin{array}{l}82.8 \\
(75.1-98.3)\end{array}$ & $\begin{array}{l}83.6 \\
(75.2-100.9)\end{array}$ \\
\hline Number of medications, median (min-max) & $\begin{array}{l}11.0 \\
(0.0-37.0)\end{array}$ & $\begin{array}{l}12.0 \\
(1.0-38.0)\end{array}$ & $\begin{array}{l}12.0 \\
(0.0-44.0)\end{array}$ & $\begin{array}{l}13.5 \\
(0.0-34.0)\end{array}$ \\
\hline Antipsychotic use, (\%) & $43(25.4)$ & $74(25.9)$ & $38(20.0)$ & $60(20.0)$ \\
\hline \multicolumn{5}{|l|}{ Diagnosis, number (\%) } \\
\hline Alzheimer's Disease & $37(23.2)$ & $80(29.3)$ & $50(28.4)$ & $91(31.1)$ \\
\hline Mixed Dementia & $39(24.5)$ & $49(17.9)$ & $25(14.2)$ & $33(11.3)$ \\
\hline Vascular Dementia & $8(5.0)$ & $10(3.7)$ & $7(4.0)$ & $10(3.4)$ \\
\hline Lewy Body Dementia & $6(3.8)$ & $6(2.2)$ & $2(1.1)$ & $3(1.0)$ \\
\hline Other Dementias & $2(1.2)$ & $5(1.8)$ & $1(0.6)$ & $2(0.6)$ \\
\hline Unspecified Dementia & $18(11.3)$ & $44(16.1)$ & $28(15.9)$ & $47(16.0)$ \\
\hline Mild Cognitive Impairment & $26(16.4)$ & $44(16.1)$ & $32(18.2)$ & $52(17.7)$ \\
\hline Unspecified Cognitive Impairment & $23(15.4)$ & $36(14.2)$ & $31(17.6)$ & $55(18.8)$ \\
\hline \multicolumn{5}{|l|}{ Living Arrangement, number (\%) } \\
\hline Alone & $16(9.5)$ & $48(16.8)$ & $25(13.2)$ & $58(19.3)$ \\
\hline Spouse and/or Child & $105(62.1)$ & $102(35.7)$ & $120(63.2)$ & $125(41.7)$ \\
\hline Other & $34(20.1)$ & $102(35.7)$ & $34(17.9)$ & $93(31.0)$ \\
\hline Unknown & $14(8.3)$ & $34(11.9)$ & $11(5.8)$ & $24(8.0)$ \\
\hline
\end{tabular}

Legend: ${ }^{\mathrm{a}} Q A P$ Quebec Alzheimer Plan 


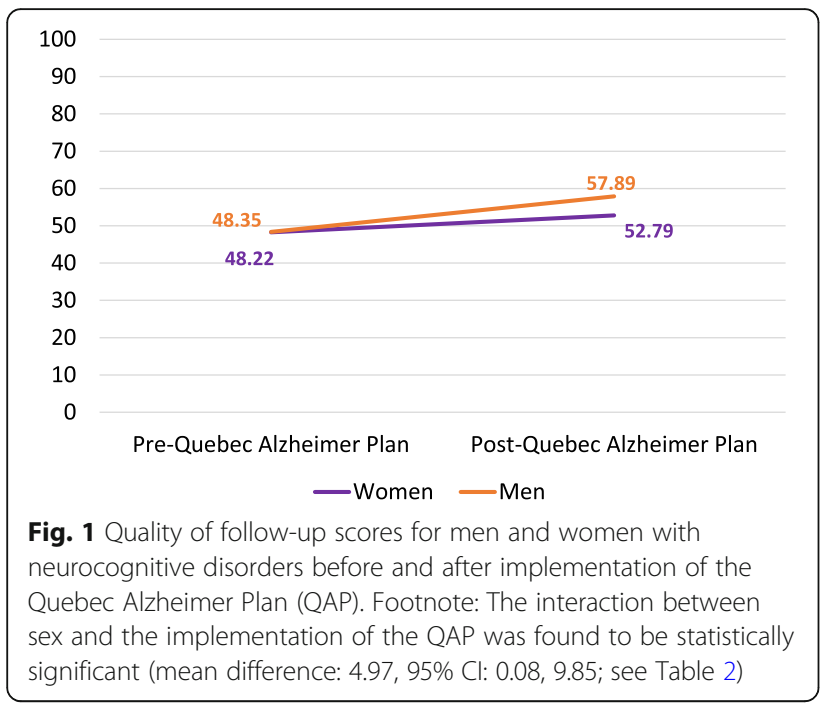

Figure 2 presents the frequency of assessments of the 10 quality of dementia care indicators in men and women before and after the QAP. Men showed greater improvement in terms of Alzheimer Society referrals, driving assessments, dementia's medication management and functional status evaluations. Home care needs, weight, and BPSD assessments increased by a greater margin in women. Frequency of cognitive testing increased in men following implementation of the QAP whereas testing decreased in women. Similarly, men were less often prescribed anticholinergics following the QAP than women. While caregiver needs assessments improved for women but decreased in men, the frequency of assessment was still higher in men followed the QAP.

\section{Conclusion}

To our knowledge, this study is the first to assess sex differences in the impact of a population-level dementia plan.

Table 2 Differential impact of the Quebec Alzheimer Plan for men and women with neurocognitive disorders

\begin{tabular}{ll}
\hline & $\begin{array}{l}\text { Mean Difference } \\
\text { (95\% Confidence Interval) }\end{array}$ \\
\hline Intercept & 52.95 \\
& $(32.77,73.12)$ \\
Men $^{\mathrm{a}}$ & 0.04 \\
& $(-3.49,3.57)$ \\
Post-QAP ${ }^{\mathrm{b}, \mathrm{c}}$ & 4.59 \\
& $(0.72,8.46)$ \\
Men $^{*}$ Post-QAP & 4.97 \\
& $(0.08,9.85)$ \\
Age & -0.05 \\
& $(-0.28,0.18)$ \\
Number of Medications & -0.03 \\
& $(-0.21,0.14)$ \\
\hline
\end{tabular}

${ }^{a}$ Reference category is women

${ }^{b}$ Reference category is pre-QAP

${ }^{c} Q A P$ Quebec Alzheimer Plan
We found that improvements in the quality of dementia care following the QAP were larger for men than for women. Among the 10 quality of care indicators assessed, we found that men had a larger improvement in five of these indicators while women improved more than men in three indicators. Changes following the QAP in two indicators were in opposite directions for men and women. This study reveals differences in quality of dementia care between men and women following a subnational dementia policy. The results may suggest inequalities of care for women compared with men in dementia strategies.

Evidence with which to compare our results were extremely scarce. We found direct comparative literature in only two indicators: absence of anticholinergic medication and assessment of functional status. Our finding that men had less frequent use of anticholinergic medication was consistent with two studies [36, 37], but inconsistent with others which found no significant difference in anticholinergic use between men and women with dementia [38, 39]. In terms of functional status assessments, our study was consistent with one other study [40], which found hospitalized older women had more assessments than older men $(9.1 \%$ of men did not have an assessment recorded, compared to $8.0 \%$ of women).

For the remaining indicators, only broader literature was found. We found that male drivers were more frequently assessed for driving than female drivers and that assessments of driving ability improved after QAP in men but not in women. This finding may be related to gendersocial roles where older drivers have been found to be more frequently men [41]. Moreover, it has been shown that women are more likely to self-regulate and stop driving than men [42]. Together, these differences may have influenced clinicians' decision to assess driving. Our results also showed that men had more frequent assessments of dementia medications. Given that Rochon et al. [39] found women were at greater risk of having serious events following prescriptions for dementia, this finding points to the need for more careful consideration of adverse medication-related events in women with dementia. Finally, women in our study had more home care needs assessment than men. While higher rates of referral or use of home care services in women have been previously reported, women also report more unmet homecare needs [43]. Further research is needed to explore whether differential use of home care adequately meets the needs of men and women with dementia.

Our study has certain limitations. We conducted a cross-sectional analysis; thus, we can conclude on association, not causality. Our study did not have the statistical power to detect differences for each indicator separately, so our analyses on each indicator are exploratory. The present study is a secondary analysis of a previous chart review [30] and as a result, we were unable to measure 


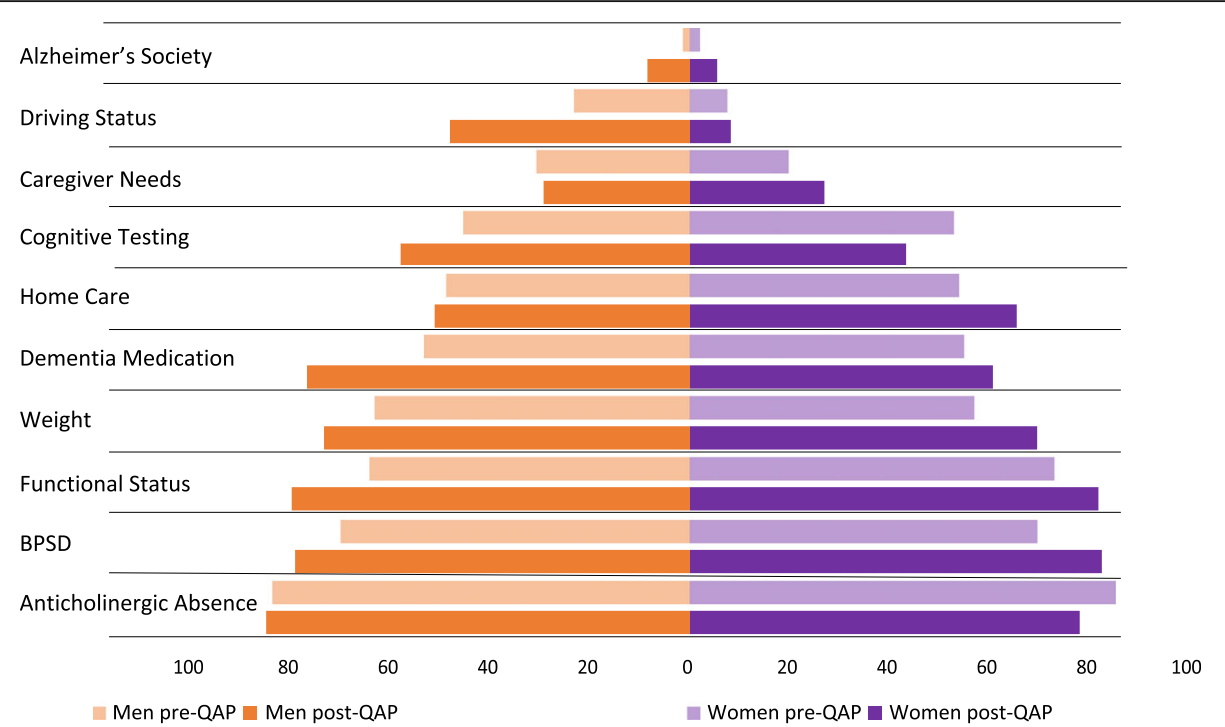

Fig. 2 Quality of follow-up indicators assessed for men and women with neurocognitive disorders before and after implementation of the Quebec Alzheimer Plan (QAP). Footnote: All indicators refer to evaluation or assessments reported in the patient charts. Anticholinergic absence refers to the absence of anticholinergic medications in the patients list of medications. BPSD stands for Behavioural and psychological symptoms of dementia

certain variables of interest, such as caregiver role or direct information on participant gender. In addition, chart review data is limited to recorded information. It also may limit our ability to inform us on gender differences, as the data recorded is often biological sex.

Though research on dementia has made considerable gains, there is a critical absence of research on sex- and gender-based differences in dementia, which in turn has led to an absence of policy and guidelines designed to best answer to the specific respective needs of men and women. This study strove to fill this important knowledge gap and highlights the importance of considering sex and gender issues in the design, implementation, and evaluation of dementia strategies and interventions. While we identified areas of inequalities in the care received, it is unclear whether this represents inequities in access to care and health outcomes. Future research should focus on better understanding sex and gender-specific needs in dementia to bridge this gap and better inform dementia strategies.

\section{Abbreviations \\ QAP: Quebec Alzheimer Plan; BPSD: Behavioural and Psychological Symptoms of Dementia}

\section{Authors' contributions}

NS, GAL, EMD, and IV contributed to the study conception and design. EMD and $\mathrm{MH}$ contributed to the analysis of results. All authors contributed to writing the manuscript, interpretation of the results, approved the version to be published and agreed to be accountable for all aspects of the work.

\section{Funding}

This work was funded by the Fonds de Recherche du Québec-Santé and the Canadian Consortium on Neurodegeneration in Aging (2014-2019) (CNA-
137794). The Canadian Consortium on Neurodegeneration in Aging is supported by a grant from the CIHR with funding from several partners.

\section{Availability of data and materials}

The datasets generated and/or analysed during the current study are not publicly available due requirements from the research ethics boards.

Ethics approval and consent to participate

Ethics approvals were obtained from the Centre Intégré Universitaire de Santé et Services Sociaux (CIUSSS) of West-Central Montreal, the CIUSSS Centre-Sud de I'île-de-Montréal, the Centre Intégré de Santé et de Services Sociaux (CISSS) de la Montérégie-Centre, the CIUSSS du Saguenay-Lac-SaintJean, the CIUSSS de l'Estrie - Centre Hospitalier de I'Université de Sherbrooke, the CISSS de Laval, and the CISSS des Laurentides. Permission to consult patient charts for research purposes was granted by the Directors of Professional Services of each clinic.

\section{Consent for publication}

Not applicable.

\section{Competing interests}

The authors declare that they have no competing interests.

\section{Author details}

'Département de Médecine de Famille et de Médecine d'Urgence, Faculté de médecine, Université de Montréal, Montreal, Canada. ${ }^{2}$ Centre de Recherche du Centre Hospitalier de l'Université de Montréal, Université de Montréal, Montreal, Canada. ${ }^{3}$ Lady Davis Institute for Medical Research, Jewish General Hospital, Montreal, Canada. ${ }^{4}$ Department of Family Medicine, McGill University, Montreal, Canada.

Received: 2 July 2020 Accepted: 15 September 2020

Published online: 06 October 2020

\section{References}

1. Gates Foundation. Goalkeepers report: examining inequality. 2019.

2. United Nations. The World's women 2010: trends and statistics. New York, Affairs DoEaS; 2010.

3. World Bank. World Development Report 2012: Gender Equality and Development 2012. 
4. Vlassoff C. Gender differences in determinants and consequences of health and illness. J Health Popul Nutr. 2007;25(1):47-61.

5. World Health Organization. Women and Health: Today's Evidence Tomorrows Agenda. Geneva: WHO Press; 2009

6. Katz SJ, Kabeto M, Langa KM. Gender disparities in the receipt of home care for elderly people with disability in the United States. Jama. 2000;284(23): 3022-7.

7. Green CA, Pope CR. Gender, psychosocial factors and the use of medical services: a longitudinal analysis. Soc Sci Med. 1999;48(10):1363-72.

8. Vaidya V, Partha G, Karmakar M. Gender differences in utilization of preventive care services in the United States. J Women's Health (2002). 2012;21(2):140-5.

9. Thompson AE, Anisimowicz Y, Miedema B, Hogg W, Wodchis WP, AubreyBassler $K$. The influence of gender and other patient characteristics on health care-seeking behaviour: a QUALICOPC study. BMC Fam Pract. 2016; 17(1):38.

10. Canadian Institutes of Health Research. Equity, diversity and inclusion resources 2020 [Available from: https://cihr-irsc.gc.ca/e/51709.html.

11. Institute of Medicine Committee on Women's Health R. Women's Health Research: Progress, Pitfalls, and Promise. Washington (DC): National Academies Press (US), Copyright 2010 by the National Academy of Sciences. All rights reserved; 2010.

12. Regitz-Zagrosek V. Sex and gender differences in health. Science \& Society Series on sex and science. EMBO Rep. 2012;13(7):596-603.

13. Nebel RA, Aggarwal NT, Barnes LL, Gallagher A, Goldstein JM, Kantarci K, et al. Understanding the impact of sex and gender in Alzheimer's disease: a call to action. Alzheimers Dement. 2018;14(9):1171-83.

14. Erol R, Brooker D, Peel E. Women and Dementia: A Global Research Review2015. Available from: https:/www.alz.co.uk/sites/default/files/pdfs/ Women-and-Dementia.pdf.

15. Prince M, Ali GC, Guerchet M, Prina AM, Albanese E, Wu YT. Recent global trends in the prevalence and incidence of dementia, and survival with dementia. Alzheimers Res Ther. 2016;8(1):23.

16. Livingston G, Sommerlad A, Orgeta V, Costafreda SG, Huntley J, Ames D, et al. Dementia prevention, intervention, and care. Lancet. 2017;390(10113): 2673-734.

17. Kessler RC, McGonagle KA, Swartz M, Blazer DG, Nelson CB. Sex and depression in the National Comorbidity Survey. I: lifetime prevalence, chronicity and recurrence. J Affect Disord. 1993;29(2-3):85-96.

18. Kramer JH, Yaffe $\mathrm{K}$, Lengenfelder J, Delis DC. Age and gender interactions on verbal memory performance. J Int Neuropsychol Soc. 2003;9(1):97-102.

19. Tschanz JT, Corcoran CD, Schwartz S, Treiber K, Green RC, Norton MC, et al. Progression of cognitive, functional, and neuropsychiatric symptom domains in a population cohort with Alzheimer dementia: the Cache County dementia progression study. Am J Geriatr Psychiatry. 2011;19(6):532-42.

20. Irvine K, Laws KR, Gale TM, Kondel TK. Greater cognitive deterioration in women than men with Alzheimer's disease: a meta analysis. J Clin Exp Neuropsychol. 2012;34(9):989-98.

21. Gambassi G, Lapane KL, Landi F, Sgadari A, Mor V, Bernabie R. Gender differences in the relation between comorbidity and mortality of patients with Alzheimer's disease. Systematic assessment of geriatric drug use via epidemiology (SAGE) study group. Neurology. 1999;53(3):508-16.

22. Nelis SM, Wu YT, Matthews FE, Martyr A, Quinn C, Rippon I, et al. The impact of co-morbidity on the quality of life of people with dementia: findings from the IDEAL study. Age Ageing. 2019;48(3):361-7.

23. Rosenwax L, McNamara B, Zilkens R. A population-based retrospective cohort study comparing care for Western Australians with and without Alzheimer's disease in the last year of life. Health Soc Care Commun. 2009; 17(1):36-44.

24. Bronskill S, Camacho X, Corbett L, Gill S, Gruneir A, Ho M, et al. Health system use by frail Ontario seniors: an in-depth examination of four vulnerable cohorts: Institute for Clinical Evaluative Sciences; 2011.

25. Lyketsos CG, Steele C, Galik E, Rosenblatt A, Steinberg M, Warren A, et al. Physical aggression in dementia patients and its relationship to depression. Am J Psychiatry. 1999;156(1):66-71.

26. Zuidema SU, de Jonghe JF, Verhey FR, Koopmans RT. Predictors of neuropsychiatric symptoms in nursing home patients: influence of gender and dementia severity. Int J Geriatr Psychiatr. 2009;24(10):1079-86.

27. Bartlett R, Gjernes T, Lotherington AT, Obstefelder A. Gender, citizenship and dementia care: a scoping review of studies to inform policy and future research. In: Health \& social care in the community; 2016.
28. Alzheimer's Disease International publication team. From plan to impact: Progress towards targets of the Global action plan on dementia2018 Jan 5, 2017. Available from: https:/www.alz.co.uk/adi/pdf/from-plan-to-impact-2018.pdf.

29. Ministère de la Santé et des Services Sociaux du Québec. Relever le défi de la maladie d'Alzheimer et des maladies apparentées : une vision centrée sur la personne, l'humanisme et l'excellence. Rapport du comité d'experts en vue de l'élaboration d'un plan d'action pour la maladie d'Alzheimer. Rapport présidé par le Professeur Howard Bergman 2009 [Available from: http://publications.msss.gouv.qc.ca/msss/document-000869/.

30. Vedel I, Sourial N, Arsenault-Lapierre G, Godard-Sebillotte C, Bergman H. Impact of the Quebec Alzheimer plan on the detection and management of Alzheimer disease and other neurocognitive disorders in primary health care: a retrospective study. CMAJ Open. 2019;7(2):E391-E8.

31. Arsenault-Lapierre G, Godard-Sebillotte C, Sourial N, Couturier Y, Bouchard P, Pilon C, et al. Le Plan Alzheimer Québécois, un plan basé sur les soins primaires / The Quebec Alzheimer Plan, a Plan Based in Primary Care. La revue de Santé Publique. 2020;Accepted.

32. Statistic Canada. Quebec [Province] and Canada [Country] (table). Census Profile. 2016 Census. . Ottawa; 2017 Released November 29, 2017. Contract No.: Statistics Canada Catalogue no. 98-316-X2016001.

33. Third Canadian Consensus Conference on diagnosis and treatment of dementia Montreal2007 [Available from: http://www.cccdtd.ca/pdfs/Final_ Recommendations_CCCDTD_2007.pdf.

34. Wenger NS, Roth CP, Shekelle P. ACOVE investigators. Introduction to the assessing care of vulnerable elders-3 quality indicator measurement set. J Am Geriatr Soc. 2007:55(S2):S247-S52.

35. Callahan CM, Sachs GA, LaMantia MA, Unroe KT, Arling G, Boustani MA. Redesigning systems of care for older adults with Alzheimer's disease. Health Aff. 2014;33(4):626-32.

36. Bierman AS, Pugh MJV, Dhalla I, Amuan M, Graeme Fincke B, Rosen A, et al. Sex differences in inappropriate prescribing among elderly veterans. Am J Geriatr Pharmacother. 2007;5(2):147-61.

37. Valladales-Restrepo LF, Duran-Lengua M, Machado-Alba JE. Potentially inappropriate prescriptions of anticholinergics drugs in Alzheimer's disease patients. Geriatr Gerontol Int. 2019;19(9):913-7.

38. Trenaman SC, Rideout M, Andrew MK. Sex and gender differences in polypharmacy in persons with dementia: a scoping review. SAGE Open Med. 2019;7:2050312119845715.

39. Rochon PA, Gruneir A, Gill SS, Wu W, Zhu L, Herrmann N, et al. Initial cholinesterase inhibitor therapy dose and serious events in older women and men. J Am Geriatr Soc. 2018;66(9):1692-9.

40. Bogardus ST Jr, Towle V, Williams CS, Desai MM, Inouye SK. What does the medical record reveal about functional status? A comparison of medical record and interview data. J Gen Intern Med. 2001;16(11):728-36.

41. Foley DJ, Heimovitz HK, Guralnik JM, Brock DB. Driving life expectancy of persons aged 70 years and older in the United States. Am J Public Health. 2002;92(8):1284-9.

42. Baines N, Au B, Rapoport MJ, Naglie G, Tierney MC. Meta-analysis of driving cessation and dementia: does sex matter? J Gerontol. 2016;73(7):1185-9.

43. Forbes DA, Jansen SL, Markle-Reid M, Hawranik P, Morgan D, Henderson S, et al. Gender differences in use and availability of home and communitybased services for people with dementia. Can J Nurs Res. 2008;40(1):39-59.

\section{Publisher's Note}

Springer Nature remains neutral with regard to jurisdictional claims in published maps and institutional affiliations.

Ready to submit your research? Choose BMC and benefit from:

- fast, convenient online submission

- thorough peer review by experienced researchers in your field

- rapid publication on acceptance

- support for research data, including large and complex data types

- gold Open Access which fosters wider collaboration and increased citations

- maximum visibility for your research: over $100 \mathrm{M}$ website views per year

At BMC, research is always in progress.

Learn more biomedcentral.com/submission 